\title{
Mafalda e a escola: representações da educação argentina em cinco tirinhas de Quino
}

\section{Mafalda and school: Argentinian education representations in five comic strips by Quino}

https://doi.org/10.34112/2317-0972a2018v36n72p43-58

\section{Raquel Cardonha Piacenti ${ }^{1}$}

Maria do Carmo Martins ${ }^{2}$

Resumo: Ainda que, na atualidade, a história em quadrinho seja reconhecida tanto pelo seu alcance quanto por ser veiculadora de ideologias e conflitos, as HQs são uma fonte ainda pouco explorada pelos pesquisadores de um modo geral. Somente nos anos 1970 surgiram trabalhos que questionaram a ausência dos quadrinhos nos discursos acadêmicos e sua classificação como gênero menor. Este artigo entende os quadrinhos como uma importante forma de manifestação cultural e de representação de uma determinada época e contexto. Nesse cenário, analisa o impacto visual e constrói relações entre Mafalda - ícone das historietas - e o cenário educacional argentino da época em que a personagem foi produzida. Além das representações do ambiente escolar, o diálogo com essa fonte documental se faz articulando estudos históricos e estudos sobre a cultura visual, reconhecendo as especificidades da fonte em suas características estéticas e como produção cultural e artística, para propor leituras e interpretações.

PALAVRAS-ChAVE: História da educação; cultura visual; história em quadrinhos.

ABSTRACT: Although comic book stories have been recognized by both its scope and the ability to communicate ideologies and conflicts, they have still been little explored as a

1. Universidade Estadual de Campinas, Campinas, SP, Brasil.

2. Universidade Estadual de Campinas, Campinas, SP, Brasil. 
source by researchers in general. Only in the 1970s studies started questioning the absence of comics of academic fields and its classification as gender less. This article considers the comics as an important cultural manifestation that represents a certain time and context. In this scenario, we have analyzed their visual impact and we have related Mafalda - the icon of historietas - and the Argentinian education at the time that was produced. In addition to the representations of the school environment, the dialogue with this source is presented by articulating historical studies and the studies on visual culture, recognizing the specificities of the source in its aesthetic characteristics and as cultural and artistic production in order to propose readings and interpretations.

KEYWORDS: History of education; visual culture; comics.

\section{INTRODUÇão}

O riso é fundamental e, talvez seja pelo lado humorístico que a maioria dos quadrinhos se sobressai. Nas últimas décadas o humor passou a ser considerado pelos historiadores como uma via para compreender as sociedades, uma vez que apresenta motivos e efeitos sociais e políticos, sendo usado para mobilizar simpatias, apoios, identidades pessoais e, intervir em lutas e conflitos (COSSE, 2014, p. 24). Dessa maneira, as HQs, responsáveis por inúmeras reflexões e gargalhadas, são também uma importante forma de manifestação cultural, cuja função fundamental é comunicar ideias e histórias. Por essa, dentre outras razões, as histórias em quadrinhos são interpretadas como importantes fontes produtoras de conceitos e, ao mesmo tempo, representações de determinada época e contexto.

As histórias em quadrinhos, compostas por imagens e textos - que, na maioria das vezes, são associados a elas - também pressupõem práticas de produção, circulação e apropriação, por parte de quem as lê e discute. Na Argentina, lugar de destaque deste artigo, surgiu, nos anos de 1960, uma nova geração de desenhistas que reformulou os espaços destinados ao humor, criando revistas e jornais como a revista Tía Vicenta, que, enfatizando o humor em tiras e caricaturas, questionou a sociedade argentina, denunciou os problemas nacionais e criticou os governos da época. O argentino Joaquim Salvador Lavado, mais conhecido como Quino, foi um artista que fez parte dessa renovação: criou Mafalda, uma personagem capaz de impactar adultos, jovens e crianças, e de mobilizar diversos setores, com histórias e posições até hoje utilizadas nas mais diversas lutas sociais. 
Vista em seu contexto de criação e potencializada como produto cultural de grande impacto para seus leitores (COSSE, 2014), a obra Mafalda é considerada uma veiculadora de ideias em um determinado contexto social e histórico argentino, mas que ultrapassa suas fronteiras. A riqueza temática desses quadrinhos de Quino torna-os um objeto de análise expressivo. Seu forte cunho de crítica política e social, a longevidade de sua produção e sua ampla circulação internacional são relevantes para nos voltarmos a essa obra já tão estudada e analisada.

Após o nascimento das tiras da pequena menina contestadora em 1963, o humor e as críticas que ela veicula transcenderam as fronteiras geográficas, consolidando seu alcance universal e expressando o sucesso da criação de Quino. Como aponta Umberto Eco (2003: XVI), o universo de Mafalda não é apenas o da América Latina, mas de todo o planeta. Além dele, Pablo Pineau (2005) a denomina como um dos ícones culturais argentinos dos anos 60 e a adjetiva como uma genial historieta, reflexo das classes médias em expansão e com um excelente frescor de trabalho educativo ${ }^{3}$.

Devido ao sucesso da obra, Mafalda é tema de inúmeras reportagens, artigos e trabalhos acadêmicos. Pesquisas se dedicaram às questões políticas e econômicas abordadas pela tira, tais como as ditaduras latino-americanas (BARALE, 2009; ROSSI et al, 2015), a Guerra no Vietnã e a Guerra Fria (ÁVILA, 2009). Os trabalhos de Eco (1974) e Cosse (2014) são também relevantes, pois apontam para a importância da personagem, sua trajetória e seus impactos na sociedade argentina, em especial para a classe média daquele país. Autores como Vergueiro (2006) e Ramos (2010) se utilizam dos quadrinhos de Mafalda para discutir o uso de HQs na escola, principalmente no ensino de linguagens. Outros, como Seide (2006) e Oliveira (2011), abordam seu uso em sala de aula nas práticas de ensino de disciplinas como língua portuguesa e história, respectivamente. Ademais, outros trabalhos, como o de Bissaco (2014), analisam a obra a partir das questões linguísticas da tira.

Quando, entretanto, nos voltamos à relação entre as tiras de Mafalda e a educação argentina, poucos são os trabalhos que procuraram investigar as formas de

3. A obra Mafalda foi traduzida para mais de vinte idiomas, alcançando países como Indonésia e Coréia. Além de corroborar para a ideia de seu sucesso, esses dados também refletem compreensão e aceitação dos temas por ela enunciados. Dessa maneira, é possível inferir que os leitores (argentinos ou não) que leem sobre os momentos escolares das personagens de Quino reconhecem-se nesse formato escolar, nas relações entre alunos e professores e no cotidiano das escolas. Usa-se itálico para se referir à obra e fonte normal para se referir à personagem Mafalda. 
representação e interlocução entre a obra e o sistema educacional daquele país, destacando-se, então, os trabalhos de Pineau (2005) e Suarez (2011).

Mafalda foi publicada em cerca de duas mil tiras, das quais destacam-se $194 \mathrm{em}$ que a escola e a educação aparecem como cenário ou assunto das personagens que compõem o enredo dos quadrinhos. Dentre estas selecionamos apenas cinco tiras para apresentar a discussão proposta, uma vez que são emblemáticas pela forma como Quino trata a educação e por trazerem elementos que se repetem e/ou dialogam com as ideias e embates do momento em que foram publicadas.

Neste artigo, a obra Mafalda se tornou uma fonte documental a partir da qual analisamos e construímos representações sobre a educação, em especial, a educação argentina ${ }^{4}$. Ironia e acidez são elementos fundamentais na constituição do humor nas tiras de Quino, que, por toda sua obra, também através do uso de exageros e críticas expressa suas visões e representações acerca da escola e do sistema educacional. Reconhecendo as especificidades da fonte documental em suas características estéticas e sua cultura artística, objetivamos compreender as representações e produções sobre a educação e a forma escolar presentes na obra.

A análise dos quadrinhos encontra respaldo no referencial da cultura visual para repensar as críticas, estéticas e ideias de educação propostos pela tira e seu autor. Em estudos recentes propostos pela cultura visual, discute-se o potencial cognitivo das imagens. O que se defende é o abandono da antiga postura de utilizá-las apenas como fontes, para um tratamento mais abrangente da visualidade. A imagem passa, então, a ser compreendida como uma representação social, forma de produção e/ ou reprodução cultural, capaz de criar símbolos de uma realidade comum. Assim, a partir de autores como Hernandez (2001), Freddman (2002) e Meneses (2003), assinala-se a importância de aprender a ver e ler os dados visuais, uma vez que a linguagem visual é considerada mais que uma forma de facilitar a comunicação, sendo também uma manifestação cultural de determinada sociedade. Dessa maneira, através do estudo da estética e das formas, a imagem passa a ser compreendida como uma experiência de produção e recepção, que transforma as informações geradas e as recebidas, alterando também, a própria percepção e modos de se visualizar.

4. Apesar de este artigo discorrer sobre a escola argentina (vivida por Quino), torna-se relevante apontar que o modelo de educação moderno, consolidado no século XIX e início do XX, prevaleceu na maioria dos países ocidentais, marcando as escolas com a tradicional postura disciplinadora, rígida, voltada para o controle dos corpos e formação integral dos cidadãos. 
Tendo isso em vista, o artigo reflete sobre processos educativos e o modo pelo qual o formato escolar tradicional, consolidado no solo argentino, foi representado e reconhecido por Quino e seus leitores; busca-se, também, a compreensão acerca do que a imagem nos informa e como ela o faz, fugindo de qualquer tentativa de utilizá-la apenas para ilustrar algo já concebido. Nesse sentido, considera-se o impacto visual e são construídas relações entre Mafalda e o cenário educacional argentino da época em que a personagem foi produzida.

\section{MAFALDA E A EDUCAÇÃO ARGENTINA}

A personagem Mafalda nos permite apresentar, através do humor e da sátira, um conjunto de temas polêmicos que fez parte do cotidiano dos argentinos nos anos 1960 e 70 . O período que abarca sua produção também representa um momento de transição na sociedade e na história da educação argentina, quando intelectuais e pesquisadores se envolveram na discussão de ideias pedagógicas e das instituições educativas (ASCOLANI, 1999, p. 18). Em 1955, Pedro Eugenio Aramburu assumiu a presidência do país, determinado a limpar o país do peronismo, eliminando sua simbologia, alterando os textos e planos de estudos, até mesmo a vida cotidiana escolar. Segundo Puiggrós (1997), as novas diretrizes educacionais voltadas ao antiperonismo se preocuparam em retirar dos ambientes escolares quaisquer alusões ao ex-presidente, ao nacionalismo exacerbado e suas práticas pedagógicas.

Além disso, durante os anos 1960, no contexto do confronto entre o capitalismo norte-americano e o socialismo soviético, a modernização econômica dos países latino-americanos entrou na pauta de organismos internacionais como a CEPAL (Comissão Econômica para a América Latina e o Caribe), que visavam avaliar a situação dos países envolvidos a fim de promover a sua industrialização. Concomitantemente, na Argentina se difundiu a ideia de que as economias latino-americanas precisavam recorrer às intervenções estrangeiras para intensificar o progresso, sinônimo de ampla industrialização. De acordo com Ianni (1970, p. 8), tal intervenção extrapolaria o setor econômico e político, abrangendo a educação, compreendida como uma ferramenta essencial desse processo modernizante.

Além da instabilidade política contínua, a Argentina - como boa parte das nações ocidentais - enfrentaria um amplo processo de modernização social e cultural, visto que as classes médias impulsionaram a homogeneização do consumo através da produção em massa, das propagandas e do marketing. Surgiram novas pautas 
nas relações sociais e de trabalho e modificaram-se as concepções de infância, paternidade e gênero. $\mathrm{O}$ sistema educacional acompanhava essas transformações, propondo à sociedade argentina um modelo educativo que unisse as influências internacionais ao desejo de modernização social.

Marcada pela uniformização dos alunos, a assimetria das relações professor-aluno, o uso de mecanismos disciplinares, de métodos avaliativos hierárquicos e discriminatórios, a escola moderna (que se consolidou no século XIX e esteve presente na maior parte do XX), nos é mostrada não de forma linear, mas de maneira bastante singular nas historietas de Mafalda. Percebem-se, nos quadrinhos, referências à visão da escola moderna como produtora e reprodutora dos conceitos, valores e anseios dominantes da sociedade em que se inserem, uma instituição que corrobora para a construção e dominação dos indivíduos.

Quino representa a educação argentina de inúmeras formas, possibilitando-nos imaginar como eram as práticas pedagógicas, o processo de alfabetização e os objetivos do sistema educacional. A personagem Mafalda é uma menina de seis anos, que frequenta o Jardim de Infância e depois o Ensino Fundamental e, por ser contestadora e atrevida, dotada de opiniões e questionamentos desconcertantes sobre $o$ que a cerca, indaga sobre o formato da educação, a forma como a professora se porta em sala, e até mesmo sobre a finalidade do conteúdo ensinado. Dado o contexto de sua criação, suas representações do ambiente e formato escolar, permeadas de humor, não retratam, mas sim expressam as visões e críticas ao modelo tradicional, vivenciado por Quino nas décadas anteriores.

Se pensarmos com Foucault (1995, s/p), poder e governo não estão atrelados somente ao Estado. Uma vez que o poder consiste em dirigir condutas, governar seria organizar e controlar as diversas formas de ações do outro, a partir de grupos e instituições diferentes. Partindo dessa reflexão, Pineau (1996, p. 230) argumenta que a escola moderna era responsável pelo governo da sociedade, embasando-se na ordem e na crença de que somente a adequação dos indivíduos ao sistema social, econômico e político levariam o país ao progresso almejado. E assim, a fim de garantir disciplina nas escola, exigia-se silêncio, formação de filas e obediência aos adultos.

Além dos comportamentos, o corpo da criança se evidencia como organismo a ser controlado e doutrinado. Visto que esse corpo não existe em "estado natural", todos os movimentos, posturas, gestos, olhares e sensações estão atreladas às lógicas sociais e culturais, que o modelam e decidem o que é ou não permitido. Definem, dentre outras coisas, as "[...] expresiones de sentimientos y emociones, 
ritos de interacción corporal, técnicas corporales, universos morales específicos, reglas de etiqueta y vestido, técnicas de mantenimiento del cuerpo, usos corporales" (SCHARAGRODSKY, 2011, p. 02). Esse processo de educação corporal era preocupação das instituições modernas, dentre elas a escola, que, com seu conjunto de práticas, participou da fabricação da cultura e do controle dos corpos infantis.

Na tira abaixo podemos observar o formato escolar marcado por esses elementos.

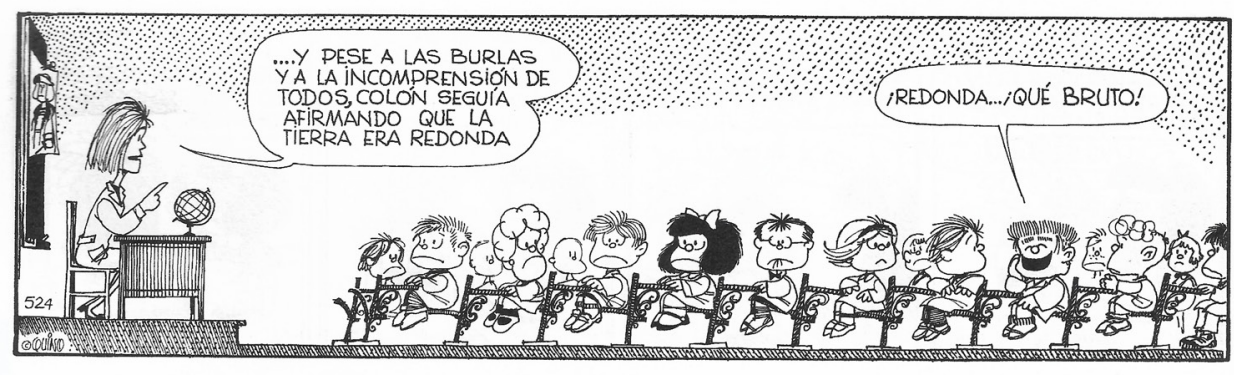

Figura 1: Tira de Mafalda

Fonte: QUINO. Toda Mafalda. Buenos Aires: Ediciones de las Flores, 1993, p 178.

Representando a relação assimétrica dos professores com os alunos, a mesa da professora é retratada como uma espécie de púlpito. Assim ficavam os docentes, em um nível mais alto do que o resto da sala, o que lhes permitiam ter uma visão privilegiada de todos os alunos e garantir que todos prestassem atenção aos seus ensinamentos. A professora se encontra sentada em sua cadeira, com o corpo rijo, e o dedo apontado para cima - símbolo muito utilizado em discursos impositivos - nos dá impressão de que ela está, ao mesmo tempo, explicando o conteúdo e garantindo a importância do que se diz. Sobre sua mesa está um globo terrestre, objeto presente na maioria das tiras e que remete à estética escolar. Os alunos por sua vez, se encontram sentados, enfileirados, todos em uma mesma posição, voltados à professora. Suas mãos e pés estão posicionados de uma mesma maneira, corroboram para a sensação de controle e obediência dos corpos. As carteiras, homogeneamente distribuídas, parecem presas ao chão, algo que, além de impedir a mobilidade dos alunos, indicava um aprendizado individual.

Contudo, esse cenário sofre uma interferência - o que produzirá o efeito de humor - Manolito interage com o ensinamento da professora, dizendo que Colombo era burro por pensar que a terra era redonda. A falta de conhecimento do aluno, 
sua ingênua participação na aula, as expressões e movimento dos corpos dos alunos geram o riso no leitor. $\mathrm{O}$ fato de Quino não ter dividido a cena em quadros, além de nos permitir ter uma visão mais ampla da sala de aula de Mafalda, produz uma sensação de continuidade nos acontecimentos da tira e também dos acontecimentos, afinal, a surpresa causada pelo comentário do colega de classe em oposição ao ensinamento sobre o formato da terra indica que nada mudou - ainda há quem pense que a terra não é redonda. E a escola continua "quadrada”...

A disciplina não era exigida somente por questões pedagógicas. Sua implantação era coerente com o objetivo primordial da escola nacional: a formação de cidadãos. Desse modo, através da ordem e do controle dos corpos infantis, introduziam-se nos alunos os valores considerados corretos e ensinava-se a obedecer a regras e normas sociais. A docilidade e submissão valorizadas por essa educação era também uma garantia de que, futuramente, não perturbariam a ordem social estabelecida. Assim, entendia-se que o papel da escola implicava a intervenção estatal e a formação dos docentes, que deveriam ser exemplos de moralidade para seus alunos. A tira abaixo nos permite apreender sobre a relação entre professores e alunos, bem como a noção do professor enquanto único capaz e responsável pela instrução dos alunos.
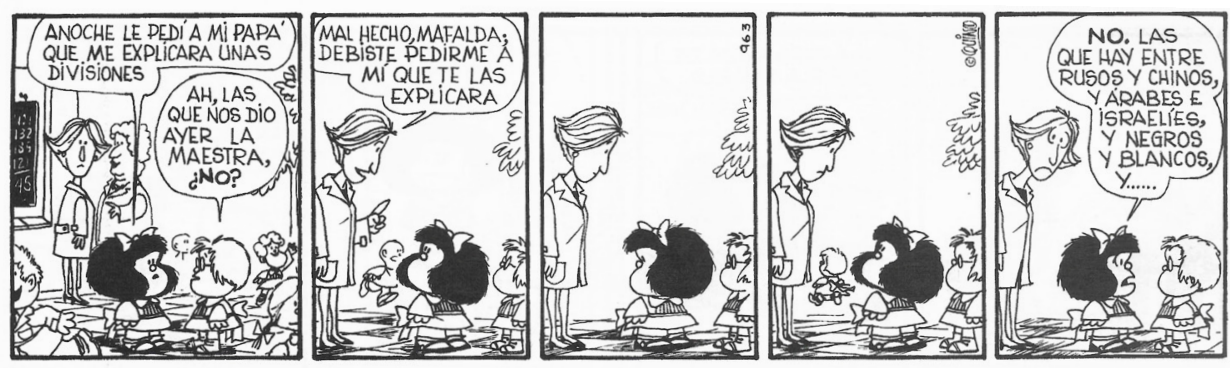

Figura 2: Tira de Mafalda

Fonte: QUINO. Toda Mafalda. Buenos Aires: Ediciones de las Flores, 1993, p. 289.

No primeiro quadro observamos duas professoras conversando enquanto observam as crianças que brincam pelo pátio do colégio. Sabemos que não se trata de uma sala de aula, pelo fato de as crianças não estarem uniformes e sentadas em suas carteiras. Algumas correm, outras se mostram sorrindo, felizes - o que também é característico das representações dos recreios. Contudo, enquanto as demais crianças se divertem, Mafalda revela à colega que na noite anterior pediu ao seu pai que lhe 
explicasse algumas divisões. A professora espanta-se com o que ouvira, seus olhos se arregalam, e ela caminha até Mafalda, questionando a atitude da menina que perguntara ao pai sobre o conteúdo escolar, quando é papel da docente lhe explicar sobre as divisões. Ela sugere que a menina deveria ter solicitado ajuda à professora. Além de sua fala dura, a professora se mantém altiva e, ao se aproximar da personagem, mantém certo distanciamento, aponta o dedo impositivo, que recrimina a atitude da aluna.

Nos próximos quadros, Mafalda, interrompida pela bronca da professora, para, volta o corpo para ela, e observa sua distância e atitude desproporcional diante do ocorrido. Seus olhos se levantam, ela analisa a professora, e com certo desdém, retoma seu diálogo com a colega. A professora se mantém firme ao seu lado, como que esperando um pedido de desculpas ou alguma forma de reparação pelo erro cometido. Entretanto, o último quadro vem nos mostrar que Mafalda não só não pediria desculpas, como a errada na cena era a professora, "detentora" do conhecimento. A protagonista explica que estava perguntando sobre as divisões sociais, culturais e raciais, e a professora adquire uma expressão de surpresa e inquietação, olhando para o leitor num pedido de ajuda diante de uma aluna tão diferenciada e da situação embaraçosa. Além da representação das funções e relações dos atores escolares, a tira produz humor pela surpresa gerada no leitor, que, assim como a colega e a professora, provavelmente imaginou que Mafalda conversava mesmo sobre as divisões matemáticas, afinal, uma criança - teoricamente inocente - não costuma indagar sobre os problemas mundiais e nacionais que acometem o mundo dos adultos. Mafalda também demonstra, nos quadros 3 e 4, desdém pela capacidade de a professora ser capaz de lhe dar respostas para questões que, de fato, a preocupam. Tanto que nem responde à intervenção da mestra.

A infância, nesse contexto tradicional, era compreendida como uma etapa inferior na vida do ser humano, sendo as crianças seres incompletos e necessitados de conhecimentos garantidos pelos adultos, no caso, seus professores. Percebemos na tira, essa missão de que os educadores se tornam os detentores de saberes e virtudes que seriam depositados nos alunos.

Além disso, era importante às professoras conservarem uma fisionomia discreta, sem exuberâncias, uma postura rígida que inspirasse respeito e cuidado. A "maestra" se transformava em uma "segunda madre", que instruía os alunos quanto aos conteúdos escolares e às condutas sociais desejadas. Esse modelo docente tem sua raiz na matriz eclesiástica da escola moderna, nos quais, como visto anteriormente, os professores herdaram a hierarquização das relações e as obrigações apostólicas e 
morais dos sacerdotes, antigos encarregados do processo de ensino. Na tira abaixo podemos visualizar as duas representações mais tradicionais a respeito da instituição de ensino e dos docentes: a escola vista como local sagrado, "templo del saber", e como um local onde os professores e alunos estabelecem uma relação similar à dos pais com seus filhos (SUAREZ, p. 49).
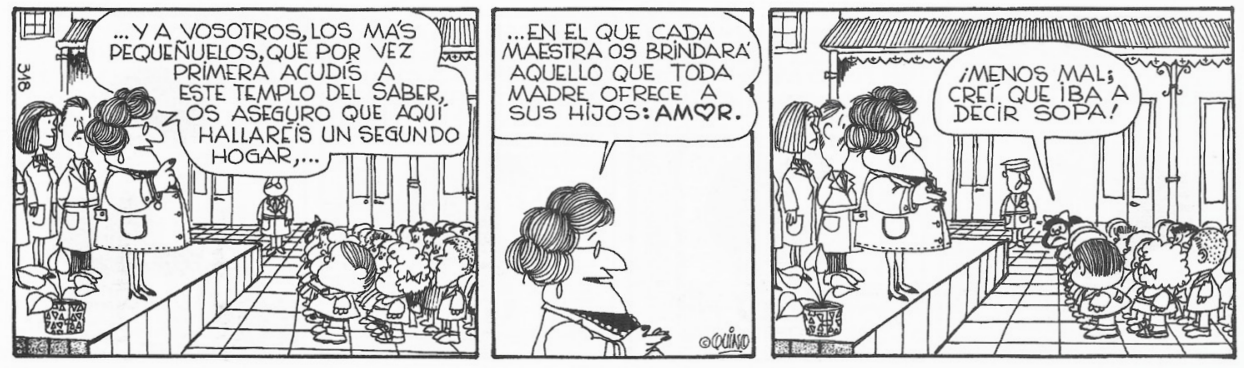

Figura 3: Tira de Mafalda

Fonte: QUINO. Toda Mafalda. Buenos Aires: Ediciones de las Flores, 1993, p. 127.

No primeiro quadro, presenciamos o primeiro dia de Mafalda na escola. Os alunos se encontram no pátio, enfileirados, ordenados e quietos, enquanto os professores estão em um palco para dar as "boas vindas". A arquitetura escolar do desenho é retilínea, e a opção gráfica de Quino nos gera a sensação de disciplina, na medida em que as janelas, portas e pisos quadrados ou retangulares, se alinham com a postura ereta dos professores e dos alunos. O segundo quadro destaca a professora/diretora da escola, uma senhora gorda, símbolo do modelo de professora argentina, com seu uniforme, óculos e penteado. Enquanto ela movimenta as mãos e sorri docemente, expõe aos novos alunos que estes agora fazem parte de um templo de saber e que podem se tranquilizar, porque cada professora "brindará aquello que toda madre oferece a sus hijos: amor".

Contudo, a nossa protagonista questionadora aparece no último quadro compartilhando sua alegria ao saber que receberiam amor, e não a sopa, como ela imaginava que fosse. A sopa, em toda a obra de Quino representa o autoritarismo, que Mafalda recusa e sofre ao engolir; e assim, a menina denuncia e critica a escola como um local autoritário, onde por trás de um discurso de amor, existia uma postura rígida, muitas vezes agressiva, preparada para moldar os alunos de acordo com os interesses da nação. Somado ao seu discurso, vemos o guarda escolar e os 
professores olhando para Mafalda com faces desgostosas, num misto de surpresa, desapontamento e atenção diante do comentário da nova aluna.

$\mathrm{Na}$ tira abaixo presenciamos um momento de avaliação que, segundo Pineau (1996, p. 234), também correspondia à lógica disciplinadora, tendo em vista que o exame, além de medir os conhecimentos apreendidos pelos alunos através da memorização e repetição, servia como castigo para comportamentos inadequados.
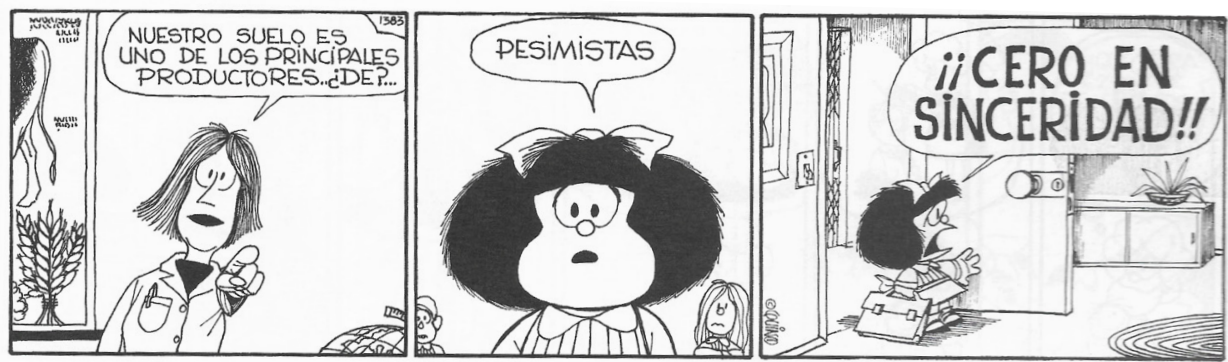

Figura 4: Tira de Mafalda

Fonte: QUINO. Toda Mafalda. Buenos Aires: Ediciones de las Flores, 1993, p. 395.

No primeiro quadro nos deparamos com a professora, em seu estilo inquisidor, perguntando sobre as principais produções argentinas. No fundo da sala vemos um quadro com uma vaca e algumas plantas, o que nos remete a uma possível aula de biologia ou geografia. Entretanto, Mafalda, a aluna interrogada da vez, responde de forma equivocada, dizendo que o solo é produtor de pessimistas, fazendo sua crítica à sociedade argentina. Ao responder, a personagem apresenta uma expressão triste, como que desapontada com o perfil de argentinos de sua época. $\mathrm{O}$ humor gerado nesse quadro se deve ao elemento político-social, num momento de avaliação escolar, além do possível reconhecimento da crítica realizada pelo autor. No último quadro visualizamos a personagem chegando a sua casa, ela abre a porta com uma expressão de desespero e tristeza, e, antes de qualquer coisa, anuncia a nota ruim na prova: "zero em sinceridade!". Novamente, o elemento humorístico se constrói no inconformismo de Mafalda, que fora sincera e considerava ser merecedora de uma nota maior por isso.

A escola moderna tradicional, produtora de conceitos e de uma estética escolar, também fora responsável pela organização do tempo - horários, recreios, duração das aulas, entre outros -, elemento fundamental para regular a relação do aluno com o espaço e tempo. O calendário escolar passa a determinar os horários de 
convívio entre os familiares, e até mesmo as datas de viagem da família de Mafalda. $\mathrm{Na}$ tira abaixo, nos deparamos com um momento de controle do tempo dentro do ambiente escolar: a campainha que sinaliza o momento de dispersão e intervalo das aulas. Mecanismo utilizado até os dias atuais, estabeleceu-se há muito como forma de comandar os corpos dos alunos. No primeiro quadro temos uma onomatopeia (ring), que como signo de representação é muito conhecido e já avisa o leitor de que a aula acabara. As crianças felizes, sorriem e ao mesmo tempo exaltam o recreio. Saem de suas carteiras e correm para o pátio, onde poderão se movimentar e brincar.
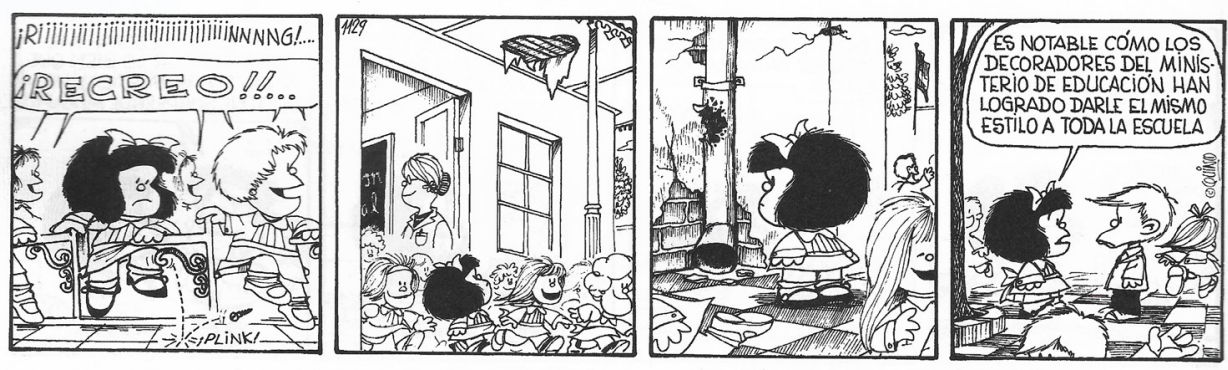

Figura 5: Tira de Mafalda publicada por EL Mundo em 12 de março de 1966 Fonte: QUINO. Toda Mafalda. Buenos Aires: Ediciones de las Flores, 1993, $p 332$.

Contudo, além de trazer mais um representação do formato escolar, Quino vai além, e aborda outras temáticas, criticando o abandono às instituições de ensino. A despeito da alegria dos outros alunos, Mafalda se mantém séria desde o primeiro quadro. Quando as crianças se movimentam, ela observa um prego que cai da sua carteira. Depois, no pátio, ela repara no teto que se desfaz, no encanamento que está quebrado, e nos muros descascados e rachados. Por fim, diante de tamanha contradição entre o momento de prazer dentro do ambiente escolar e a preocupação presente nas expressões da personagem, no último quadro Mafalda desabafa com seu colega Felipe sobre o descaso com a edificação da escola. Os detalhes do desenho nos permitem verificar esse processo de deterioração da escola e inferir uma crítica ao abandono da educação por parte das autoridades políticas. Além disso, a própria personagem interage com as ruínas e a degradação ao denominar o abandono do edifício como um trabalho dos "decoradores do ministério da educação".

A partir do estudo dos elementos da cultura material escolar, Pablo Pineau e Susana Di Pietro (2008) traçam a geometria da vida escolar argentina, considerada 
por eles como quadrada e asséptica, caracterizada pelos tradicionais jalecos brancos, as maletas, os bancos e carteiras equidistantes, os mapas-múndi, cadernos, entre outros objetos que fazem parte dessa vida escolar ${ }^{5}$. As tirinhas da obra Mafalda também nos permitem visualizar essa estética escolar problematizada e apresentada pelas imagens de Di Pietro.

Ainda, na maioria das tiras de Mafalda que trazem a sala de aula, podemos observar colado nas paredes um mapa da Argentina, frisando a importância da incorporação da noção de Nação pelos alunos, dentro no sistema tradicional de ensino argentino. Em algumas tiras as paredes possuem fotografias dos políticos e importantes homens argentinos, apresentados como heróis nacionais, uma vez que o ensino de História era transmitido a partir de epopeias, sem articulação entre os acontecimentos. Quino, ao longo de sua obra, colabora com nosso entendimento sobre a matéria que Mafalda está aprendendo através da composição de cenário, seja pelo quadros na parede, pelo globo, desenho de animais, plantas, entre outros.

Dessa maneira, ao passo que as tirinhas de Mafalda nos assinalam aspectos da educação argentina do período, de seus questionamentos e práticas escolares, elas também são parte da memória escolar dos argentinos, que, através dos desenhos, são remetidos a imagens, cores, acontecimentos e sensações de sua própria experiência escolar. A escola, então, pode ser compreendida como um espaço de imposição de determina estética, voltada para padronização dos alunos dentro do que era estipulado como aceitável e bom para a sociedade. Conforme Pineau (2008), a estética escolar permite que, partindo de um mesmo molde, unifiquem-se as experiências escolares, o modo de como se portar, o vestuário, o mobiliário, os comportamentos dos alunos e dos professores. Ademais, a escola vista como produtora de sensibilidades, de noções de beleza, limpeza, virtudes e valores, não é ingênua na maneira como pensa sua estética, e utiliza-a justamente para introduzir tais noções aos alunos que ali se encontram.

Nesse sentido, é possível relacionar a escola de Mafalda com os formatos escolares vividos até os dias atuais em escolas argentinas, brasileiras, e dos mais diversos

5. No livro Aseo y presentación: un ensayo sobre la estética escolar, Pineau e Di Pietro refletem sobre a estética escolar. Di Pietro retratou, a partir de fotografias de escolas públicas e particulares de Buenos Aires da década de 1970, os ambientes escolares, as práticas, os alunos e funcionários que compunham as cenas escolares do período. Da mesma forma, quadrinhos que trazem o vestuário dos alunos e os materiais de sala nos permitem visualizar e questionar o significado desses objetos e espaços que hegemonizam a forma como a escola é vivida, recordada e identificada, pelos leitores. 
países. A estética escolar, na medida em que padronizou os alunos e objetos, colaborou para a consolidação do modelo tido como tradicional, apresentado por Quino, mas vivenciado por todos, em seus respectivos momentos escolares. A despeito dos divergentes conteúdos, formas de aplicação e castigos corporais (hoje não mais existentes), permanecem os elementos estéticos retilíneos, o espaço de sala de aula com carteiras enfileiradas, as relações hierárquicas entre professores e alunos, métodos avaliativos, o uso de uniformes, sinalizações, medição de tempo, e rigidez quanto à postura dos alunos.

Mafalda reflete, assim, a realidade vivida naquele momento histórico, baseando suas preocupações, críticas e ideologia em experiências concretas, visto que muito do que é produzido se pauta em memórias e vivências do próprio autor. Ao tratar de aspectos que envolvem o seu contexto imediato, Quino consegue captar de maneira ímpar as questões mais relevantes do momento em que vive, expondo-as por meio da imprensa gráfica. A personagem Mafalda é, desta maneira, um registro histórico e um sujeito histórico. É nesse sentido que procuramos compreender as HQS não apenas como fontes informativas, mas também como produção cultural, que possui capacidade de ação na sociedade em que se insere, e Mafalda, se torna, desse modo, um instrumento para compreender um tempo e uma linguagem específica.

\section{REFERÊNCIAS}

ASCOLANI, A. La Educación en Argentina. Estudios de Historia. Rosario: Ediciones del Arca, 1999. ÁVILA, G. 1968: ideologia e contestação através das tiras de Mafalda. Porto Alegre: UFRGS, 2009. BARALE, A. Mafalda: el humor gráfico según Quino. Revista Fuentes Humanísticas. Dossier La historieta gráfica: cómic, tebeo, y similares aspectos técnicos y de contenido en casos particulares, Ciudad de México, n. 39, p. 27-46, 2009.

BISSACO, C. Linguística de corpus: padrões léxico-gramaticais e sentidos metafóricos na obra Mafalda. Revista Educação e Linguagens, Campo Mourão/PR, v. 3, n. 4, p. 139-154, jan./jun. 2014. Disponível em: <http://www.fecilcam.br/revista/index.php/educacaoelinguagens/article/ viewFile/658/394>. Acesso em: 20 ago. 2017.

COSSE, I. Mafalda: historia social y política. Ciudad Autónoma de Buenos Aires: Fondo de Cultura Económica, 2014.

DUSSEL, I.; CARUSO, M.; PINEAU, P. La escuela como máquina de educar: tres escritos sobre un proyecto de la modernidad. Buenos Aires: Paidós, 2013.

ECO, U. Mafalda la disconforme. In: Quino. Y digo yo. Barcelona: Pala, 1974. .Prefácio. In: Quino. Toda Mafalda: da primeira à última tira. São Paulo: Martins Fontes, 2003. 
FOUCAULT, M. O sujeito e o poder. In: DREYFUS, H. L.; RABINOW, P. Michel Foucault, uma trajetória filosófica. Para além do estruturalismo e da hermenêutica. Tradução de Vera Portocarrero e Gilda Gomes Carneiro, com revisão de Vera Portocarrero. Rio de Janeiro: Forense Universitária, 1995. p. 231-249. Disponível em: <http://www.uesb.br/eventos/pensarcomfoucault/leituras/osujeito-e-o-poder.pdf $>$. Acesso em: 23 nov. 2016.

FREEDMAN, K. Cultura visual e identidad. Cuadernos de Pedagogía. Barcelona, n. 312, p. 59-61, 2002. HERNANDEZ, F. La necesidad de repensar la educación de las artes visuales y su fundamentación en los estudios de Cultura Visual. Congreso Ibérico de Arte-Educación, Porto/Portugal, nov. 2001. Disponível em: < https://docs.google.com/document/d/1of NjHTXbnCiC_

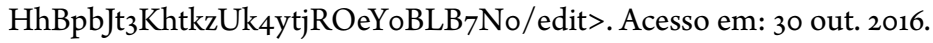

IANNI, O. Imperialismo y Cultura de la violencia en América Latina. México: Siglo XXI, 1970.

MENESES, U. Fontes visuais, cultura visual, História visual. Balanço provisório, propostas cautelares. Revista Brasileira de História. São Paulo/SP, v. 23, n. 45, p. 11-36, julho. 2003.

OLIVEIRA, C. Mafalda na aula de História: a crítica aos elementos característicos da sociedade burguesa e a construção coletiva de sentidos contra-hegemônicos. 2011. Dissertação (Mestrado em Educação)- Faculdade de Educação, Universidade do Estado do Rio de Janeiro, Rio de Janeiro, 2011.

PINEAU, P.; DI PIETRO, S. Aseo y presentación: un ensayo sobre la estética escolar. Buenos Aires: Edición de autor, 2008.

PINEAU, P. La escuela en el paisaje moderno. Consideraciones sobre el proceso de escolarización. In: CUCUZZA, H. et al. Historia de la educación en debate. Buenos Aires: Miño y Dávila editores, 1996. .'Otra vez sopa": Imágenes de la infancia y escuela en Mafalda. Procesos: Revista Ecuatoriana de Historia, n. 22, p. 153-162, 2005. Disponível em: http://revistaprocesos.ec/ojs/index.php/ojs/ article/view/233/302. Acesso em: 20 out. 2017.

PUIGGRÓS, A. Qué pasó en la educación argentina. Desde la conquista hasta el menemismo. Buenos Aires: Kapelusz, 1997.

QUINO. Toda Mafalda. Buenos Aires: Ediciones de la Flor, 2007.

RAMOS, P. Bienvenido: um passeio pelos quadrinhos argentinos. Campinas: Zarabatana Books, 2010. ROSSI, K.; HENN A; GRÜMM, C. A. F.; LIMA, A. B. M. Malfada, a menina que questionou o mundo: arte sequencial como forma de resistência durante os regimes militares da América do Sul (19641973). IV FICE - Feira de Iniciação Científica e Extensão. Instituto Federal Catarinense, Videira, SC, 2015. Disponível em: <http://videira.ifc.edu.br/fice/wp-content/uploads/sites/27/2015/11/MAFALDAA-MENINA-QUE-QUESTIONOU-O-MUNDO-arte-sequencial-como-forma-de-resistênciadurante-os-regimes-militares-da-América-do-Sul-1964-1973.pdf>. Acesso em: 10 out. 2016.

SCHARAGRODSKY, P. El cuerpo en la escuela. Revista Explora. Las Ciencias En El Mundo Contemporáneo. Programa de Capacitación Multimedial. Buenos Aires: Ministerio de Educación, Ciencia y Tecnología, 2011. Disponível em: <http://ceip.edu.uy/IFS/documentos/2015/sexual/ materiales/pedagogia-elcuerpoenlaescuela/pedagogia-elcuerpoenlaescuela.pdf $>$. Acesso em: 16 mar. 2017.

SEIDE, M. As histórias de Mafalda e o ensino de Língua Portuguesa. Revista Trama, vol. 2, n. 3, p. 105-117, 2006. Disponível em: <http://e-revista.unioeste.br/index.php/trama/article/ view/277/204>. Acesso em: 20 ago. 2017. 
Mafalda e a escola: representações da educação argentina em cinco tirinhas de Quino

SUAREZ, M. La representación de la educación en Mafalda. 2011. Dissertação (Mestrado em Ciencias de la Comunicación)- Facultad de Ciencias Sociales, Universidad de Buenos Aires, Buenos Aires, 2011.

VERGUEIRO, W. A pesquisa sobre as histórias em quadrinhos na universidade de São Paulo: Análise da produção de 1972 a 2005. São Paulo: Editora USP, 2006.

\section{SOBRE AS AUTORAS}

Raquel Cardonha Piacenti é graduada em História (Universidade Estadual de Campinas) e realiza Mestrado em Educação (Universidade Estadual de Campinas). Participa do Grupo de Pesquisa Memória, História e Educação, na linha de Pesquisa Educação e História Cultural desta mesma instituição. Professora da História na Educação Básica (rede privada de Campinas), pesquisa a história da educação escolar, tomando-a em suas manifestações culturais como em quadrinhos e cartoons. Interessa-se ainda pela história da educação latino-americana. Bolsista CNPq.

E-mail: raquelpiacenti@gmail.com.

Maria do Carmo Martins é graduada em História (Universidade Estadual de Campinas), tem Mestrado em Educação (Universidade Estadual de Campinas), Doutorado em Educação (Universidade Estadual de Campinas) e Pós-doutorado em Educação (University of Brighton, UK). É professora da Universidade Estadual de Campinas, junto ao Departamento de Educação, Conhecimento, Linguagem e Arte e coordenadora do Grupo de Pesquisa Memória, História e Educação. Tem experiência na área de História da Educação, com ênfase em história do currículo, saberes e disciplinas escolares; história da escola e cultura material escolar.

E-mail: carminhapousa@gmail.com.

Recebido em 08 de setembro de 2017 e aprovado em 13 de outubro de 2017. 